\title{
В.C. КОЗОПАС
}

\section{СОВРЕМЕННЫЕ СПОСОБЫ И МЕТОДЫ ЛЕЧЕНИЯ ПЕРЕЛОМОВ КОСТЕЙ ТАЗА}

\author{
Львовский национальный медицинский университет имени Данила Галицкого, \\ Украина
}

В течение последних десятилетий проблема травматизма в целом и повреждений таза в частности, включая множественные и сочетанные травмы, остается одной из актуальнейших не только в травматологии и ортопедии, но и в других сферах хирургии, а также в реаниматологии, организации здравоохранения. При анализе структуры политравмы повреждения таза констатируются в 17-39\% случаев. Несмотря на такую частую верификацию травм таза, консервативные и хирургические методы лечения этой патологии далеко не всегда приводят к положительным результатам. Летальность при сочетанных повреждениях таза может достигать $80 \%$, среди пациентов, перенесших травму таза, до $50 \%$ становятся инвалидами.

Обзор литературы по вопросам диагностики и лечения переломов костей таза позволит ознакомить специалистов, занимающихся этой проблемой, с современными классификациями переломов костей таза, со стандартами обследования и лечения пострадавших, с принципами медицинской эвакуации и с возможностями оптимизации оказания медицинской помощи пострадавшим с переломами тазового кольца. Показано, что оказание медицинской помощи пострадавшим с повреждениями таза, особенно с множественной и сочетанной травмой, на догоспитальном и госпитальном этапах нуждается в разработке эффективных методов обезболивания, введения противошоковых жидкостей на месте происшествия, создания унифицированных средств иммобилизации, а также пересмотре организационных мероприятий касающихся оказания медицинской помощи на догоспитальном и госпитальном этапах.

Ключевые слова: переломы костей таза, политравма, жертвы, иммобилизация, место происшествия, способ лечения, догоспитальный и госпитальный этапы

In recent decades, the problem of injuries in general and the pelvic damages in particular, including multiple and combined injuries, remains one of the most urgent not only in traumatology and orthopedics, but also in other fields of surgery, as well as reanimatology and health organization. Analyzing polytrauma structure the pelvic damages are observed in $17-39 \%$ of cases. Despite such frequent verification of pelvic injuries, conservative and surgical treatment of this disease does not always lead to positive results. In the case of combined pelvic injuries Mortality may reach up to $80 \%$, among the patients who have undergone pelvic injury the invalids became up to $50 \%$.

The literature review on the diagnosis and treatment of pelvic fractures permits to inform the specialists, dealing with this issue, about current classification of pelvic fractures along with the standards of examination, treatment, principles of medical evacuation and optimization of medical aids orientated on patients with pelvic ring fractures. It is shown, that providing emergency care to the victims with pelvic injuries, especially with multiple and combined trauma at the prehospital and hospital stages, requires the development of techniques that are effective for pain control, the administration of anti-shock fluids at the accident site, creating unified facilities of immobilization, as well as the revision of organization of medical care providing in these cases.

Keywords: fractures of the pelvis, polytrauma, victims, immobilization, accident site, method of treatment, prehospital and hospital stages

Novosti Khirurgii. 2016 Nov-Dec; Vol 24 (6): 601-609

Current Techniques and Methods of the Treatment of Pelvic Fractures

V.S. Kozopas

\section{Введение}

Пострадавшие с повреждениями таза, особенно с множественной и сочетанной травмой, являются одним из самых тяжелых и сложных контингентов больных на всех этапах лечения. С клинической точки зрения найболее опасна группа пострадавших с нестабильными повреждениями таза (переломами и повреждениями с нарушением целостности обоих отделов тазового кольца), в которых с первых минут после травмы в наибольшей мере проявляются как повреждения организма, нанесенные механическим воздействием на таз, так и общие, обусловленные повреждением сегментов опорно-двигательной системы (ОДС), а также других органов и систем [1].

Чаще всего переломы костей таза сочетаются с травмой органов малого таза, а именно мочевого пузыря и уретры [2]. Повреждения органов брюшной полости при переломах и разрывах костей и сочленений таза наблюдаются у 10-20\% пострадавших. Закрытая травма груди встречается у $30 \%$ пострадавших с повреждени- 
ями тазового кольца, сочетание повреждений таза с ЧМТ отмечаются у 30-40 \% пострадавших, а сочетание повреждений ОДС и травмы таза у $40 \%$ пострадавших [3].

Цель - отразить современное состояние проблемы диагностики и лечения переломов костей таза, включая множественные и сочетанные травмы, указать современные тенденции классификации переломов костей таза, принципы медицинской эвакуации и возможности оптимизации оказания медицинской помощи пострадавшим с переломами костей тазового кольца.

\section{Оказание медицинской помощи пострадавшим с переломами костей таза на догоспитальном этапе}

Из числа причин тяжелых множественных и сочетанных повреждений ведущими являются травмы в результате дорожно-транспортных происшествий (ДТП). Рост количества и скорости транспортных средств, увеличение числа участвующих в автомобильном движении лиц, а также водителей с недостаточным опытом вождения обусловили рост дорожно-транспортного травматизма. В Украине существует утвержденная Министерством здравоохранения трехэтапная схема лечения пострадавших: 1 этап оказание помощи на месте происшествия, 2 этап - оказание помощи на пути транспортировки в лечебное учреждение, 3 этап оказание помощи в лечебном учреждении [4]. Важным фактором, влияющим на результаты лечения является срок начала оказания первой медицинской помощи. В случаях оказания первой медицинской помощи пострадавшим в первые 9 минут после происшествия их выживание составляет 90\%, через 18 минут - только $15 \%$ [5]. В условиях ДТП первая медицинская и первая врачебная помощь оказывается со значительным опозданием в $40 \%$ случаев. В этих обстоятельствах на месте происшествия погибает 58-62\% пострадавших [6]. Основной причиной такого опоздания является несвоевременный вызов бригад специализированной медицинской помощи (СМП), удаленность места ДТП от станции скорой медицинской помощи или больницы СМП, неудовлетворительное состояние дорог и т.П. Не соблюдается правило «золотого часа» оказания квалифицированной и специализированной медицинской помощи, особенно пострадавшим с политравмой [7, 8]. В Европейских странах наибольшее распространение получила германская модель организации помощи при травмах. Основными принципами этой системы являются: своевременность - вре- мя доставки пострадавшего в травматологический центр находится в пределах 15-20 минут, преемственность догоспитального и госпитального этапов, комплексность - респираторная поддержка, инфузионно-трансфузионная терапия, обезболивание, иммобилизация [9].

Среди объективных причин, которые лежат в основе диагностических ошибок на догоспитальном этапе, в первую очередь необходимо отметить сложность и невозможность полного обследования пострадавших, находящихся в тяжелом состоянии, с нарушением сознания и тяжелым шоком. Кроме этого, важным фактором является дефицит времени наблюдения, ограниченность арсенала методов диагностики и в некоторых случаях - недостаточная квалификация врачей, оказывающих помощь на догоспитальном этапе. Так, в целом среди пострадавших с тяжелыми множественными и сочетанными переломами костей таза в течение первых 3 часов с момента травмы уровень смертности достигал 30-55\%, из них 1-10\% умирали при транспортировке [10]. По данным других авторов, при политравме в сочетании с переломами таза на месте происшествия погибает $60 \%$ пострадавших и $1 \%$ от общего числа при транспортировке [11]. В поздние сроки при повреждении костей таза уровень летальности составил от 10-42\% случаев, в группе пострадавших с сочетаной травмой - до $72 \%$ $[12,13]$. Приоритет среди причин смертельных исходов у пострадавших с переломом костей таза (50-70\%) принадлежит травматическому и геморрагическому шоку. При его констатации на догоспитальном этапе погибает более 65-70\% травмированных. На втором месте находится кровотечения как причина смертельного исхода (20-25\% случаев) [14].

Анализ данных, характеризующих объем оказания медицинской помощи пострадавшим в остром периоде, свидетельствует о том, что только в 33,5\% наблюдений он был достаточным и соответствовал текущему уровню оказания помощи [15]. В период транспортировки пострадавших в машинах скорой медицинской помощи из-за отсутствия средств в $30 \%$ случаев транспортная иммобилизация не проводится, еще в 40-50\% она проводится с нарушением основных правил. Транспортировка пострадавших с политравмой без достаточной иммобилизации и обезболивания губительны для них. Значительное количество пострадавших с политравмой доставляется в лечебные учреждения на малых стандартных носилках, что является серьезным недостатком. Для транспортировки необходимо использовать универсальные шины-носилки, которые позволяют зафикси- 
ровать все тело и конечности, и полноценное обезболивание при необходимости проведения интенсивной терапии. Реанимационные мероприятия и обезболивание также выполняются не в полном объеме. Кроме того, доставка пострадавших в приемное отделение лечебных учреждений и оказание им квалифицированной и специализированной медицинской помощи также задерживается и усложняется из-за недостаточного и малоинформативного экстренного оповещения этих лечебных учреждений [16].

\section{Современные средства транспортной иммобилизации пострадавших с переломами костей таза}

Полноценная иммобилизация поврежденных сегментов и пострадавшего является важным этапом противошокового комплекса. Кроме того, она предотвращает возможность дальнейшей травматизации и вторичного смещения отломков, углубление болевого синдрома, вероятность повреждения нервных стволов и магистральных сосудов, уменьшает возможность возникновения жировой эмболии. В комплексе лечебных мероприятий догоспитального этапа на протяжении последних двух десятилетий используют стабилизирующую укладку таза, аппарат для фиксации половин таза, надувную транспортно-лечебную шину для таза и нижних конечностей, импровизированный тазовый пояс для экстренных случаев. Рациональной является разработка Донецкого научно-исследовательского института травматологии и ортопедии (ДНИИТО) и кафедры травматологии и ортопедии Донецкого национального медицинского университета (ДонНМУ) транспортно-лечебной шины для пострадавших с повреждениями таза и нижних конечностей, которая способствует не только уменьшению болевого синдрома и эффективности реанимационных мероприятий в целом, а также уменьшает сроки стабилизации показателей гемодинамики [17].

Достаточно рациональным и патогенетически обоснованным мероприятием, по мнению В.В. Колесникова с соавт. [18], в практике лечения пострадавших с нестабильными повреждениями таза и интенсивной кровопотерей является включение в комплекс противошоковых мероприятий догоспитальной медицинской помощи противошокового костюма (ПШК) «Каштан». Аналогами ПШК «Каштан» являются противошоковые костюмы: MAST (Military anti-shock trousers, medical antishock trousers); PCPD (Pneumatic counter pressure device); PASG (Pneumatic anti - shock garment); PRS - (Pneumatic rubber suit), «Anti-G» suit. B
1977 году комитет по травмам Американской коллегии хирургов включил MAST в список необходимого оборудования, которое используют на догоспитальном этапе. Некоторые сокращения использования MAST во всех развитых странах, в том числе в США, связаны с тем, что за последние 20 лет создана система травматических центров, которая обеспечивает 15 минутную доставку пострадавшего в госпиталь [19]. Принцип действия ПШК заключается во внешней пневмокомпрессии нижней половины тела, которая приводит к перераспределению кровотока (аутогемотрансфузии) в пользу вышележащих жизненно важных органов. Использование ПШК «Каштан» на ранних этапах интенсивной терапии шока выявило положительный эффект, который проявляется в повышении системного артериального давления. Результаты применения ПШК были лучше в тех случаях, когда пневмокомпресию создавали до введения симпатомиметиков и когда объем предыдущей неэффективной инфузионной терапии не превышал 3-4 литра, то есть когда не успевали развиться нарушения гомеостаза, которые не поддаются терапии. Однако ПШК ограничивает доступ к животу и нижним конечностям, которые могут быть повреждены, вызывает некроз кожи, ишемию ног, приводит к необходимости ампутации при их переломах. Противопоказания (относительные): тампонада сердца, сдавление головного мозга при ЧМТ; показания для лапаротомии - неустраненный напряженный пневмоторакс, беременность [20].

\section{Методы лечения переломов костей таза}

В процессе транспортировки пострадавшего необходимо проведение инфузионной терапии путем струйного вливания кристаллоидных и коллоидных инфузионных растворов. В приемном и реанимационном отделениях больницы адекватная по объему, скорости и составу инфузионная терапия включает применение 2-3 литров кровезаменителей в виде коллоидных и кристаллоидных растворов, введенных под давлением с суммарной скоростью 100-200 мл/мин, причем 3 литра кровезаменителей стараются ввести в первые 10 минут. Это позволяет через 10-15 мин поднять АД до 100-110 мм рт. ст. и выше. В дальнейшем вливают не менее 2 л. плазмы и свежецитратной крови со сроком хранения не более 2-х суток [21]. По данным M.S. Failinhera, P.L.J. McGanty [22], если адекватная инфузионная терапия не стабилизирует гемодинамику, рекомендуется провести дополнительные мероприятия (диагностический перитонеальный лаваж, лапароскопию, УЗИ, 
ангиографию, внешний остеосинтез и лапаротомию). При безуспешной интенсивной инфузионной терапии в течение 1-2 часов, в случаях терминального состояния пострадавшего, или шока 3-й степени в результате кровопотери, при систолическом давлении, не поднимающемся выше 60-65мм рт.ст., необходимо предусматривать возможность повреждения магистральных сосудов таза. В таких случаях необходимо проводить или расширять лапаротомию, потому что сохранение такой гипотензии длительное время приводит к необратимому шоку. Если во время операции есть возможность собрать кровь из полости, необходимо проводить реинфузию как главное экстренное реанимационное мероприятие [23].

Однако в настоящее время получил широкое признание принцип, согласно которому перед лапаротомией выполняется внешний остеосинтез, поскольку лапаротомия снижает давление в забрюшинном пространстве после его раскрытия и приводит к потере тампонады и ускорению кровотечения. Поэтому, по показаниям к экстренной лапаротомии перед рассечением кожи должен быть наложен аппарат внешней фиксации (АВФ) [24].

Результаты лечения повреждений таза зависят от многих факторов, начиная от тяжести травмы, возникающих осложнений, способов лечения и заканчивая степенью восстановления функции. На сегодняшний день разработано и предложено более 50 классификаций оценки тяжести состояния пострадавших и тяжести политравмы. Многие травматологи полагают, что повреждения тазового кольца и переломы вертлужной впадины нельзя объединять в одной классификации, так, как для диагностики и лечения этих повреждений применяються различные методы, тактика, хирургические доступы, средства фиксации [25]. Классификация E. Letournel (1993), а также созданная на ее базе классификация группы AO/ASIF применяется для переломов вертлужной впадины. Одной из самых распространенных является классификация M. Tile (1980), соединившая в себе ряд особенностей повреждений, учитывающая как возможные зоны разрывов тазового кольца, так и степень нестабильности таза [26]. При этом данная классификация позволяет осуществлять решение вопросов лечебной тактики и прогноза исходов травмы. Классификация (АО) $\mathrm{AO} /$ ASIF, предложенная в 1990 году, соединяет концепции направления травматического воздействия и стабильности и в то же время дает возможность выбора способа лечения и прогноза ближайших и отдаленных результатов.

Тяжесть повреждений оценивают по шка- лам ВПX-П, ISS, PTS. По данным литературы, при повреждениях тазового кольца (тип А) переломы таза целесообразно лечить консервативными методами, тип В - консервативно или с применением АВФ [27]. При травмах тяжелой и средней тяжести, при нестабильных повреждениях костей таза (тип С), после выполнения неотложных хирургических вмешательств на органах грудной клетки, живота и других внетазовых структур и первичной стабилизации простыми АВФ в отдаленном периоде (2-3 суток) накладывают расширенный АВФ более сложной конструкции [28]. Результаты исследований по лечению повреждений таза свидетельствуют о преимуществе методов внешней фиксации В.Н. Пастернака с соавт. [29].

В странах Европы отдают предпочтение методам внутреннего стабильно функционального остеосинтеза, а аппараты внешней функции или тазовые щипцы рекомендуют для стабилизации костей таза при оказании неотложной помощи в первый «золотой час в шоке» [30].

В первый час после госпитализации пациентам в фазе шока и в реанимации, у которых наблюдается вертикальная и ротационная нестабильность, смещение в заднем полукольце более 1 см и обусловленная этим гемостатическая нестабильность, рекомендуется наложение аппарата внешней фиксации (АВФ) при переломах переднего полукольца, при переломах заднего полукольца - щипцов Ganz, при переломах переднего и заднего полукольца щипцов Ganz и АВФ [31].

Так как накопление массивной гематомы при нестабильных повреждениях таза способствует увеличению внутритазового пространства, важно экстренно уменьшить его путем одномоментной репозиции и стабилизации таза, как минимум скелетным вытяжением, или еще лучше - тазовыми щипцами [32] или спицей или стержневым аппаратом внешней фиксации [33]. Ранний остеосинтез таза с помощью AВФ или щипцов Ganz достигает двух целей: 1) уменьшает внутренний тазовый объем, снижает или останавливает кровотечение из костей и венозных сплетений, создавая внутритазовую тампонаду; 2) уменьшает или устраняет болевые раздражения [34]. Наложение щипцов и АВФ соответствующей конструкции не препятствует выполнению лапаротомии. Многие клиницисты проводят внешнюю фиксацию при всех нестабильных переломах типа С (по классификации AO-Tile) непосредственно при поступлении пострадавшего на основании того, что «такие переломы должны рассматриваться как потенциально летальные». Стабильный остеосинтез костей таза проводят в первые сутки, с целью не 
только восстановления анатомической целостности таза и обеспечения гемостаза, но и для снижения посттравматической интоксикации. Внедрение АВФ для фиксации таза позволило существенно улучшить результаты лечения и снизить смертность [35]. Многие авторы отмечают преимущество оперативного лечения нестабильных повреждений тазового кольца перед консервативным. Оперативные вмешательства при повреждениях таза и тазовых органов с учетом состояния пострадавшего и характера травм могут проводиться в определенной последовательности. Так, А.М. Анкин с соавт. разделяют оперативные вмешательства на неотложные, срочные, второй очереди и отложенные во времени [36].

Нестабильные повреждения таза донецкая школа травматологов [37] считает показанными для оперативной стабилизации первой очереди. При нестабильных повреждениях таза, особенно типа С, общее состояние пострадавшего не позволяет проводить внутреннюю фиксацию как наиболее совершенный способ остеосинтеза. Логично предложение применять двухэтапный метод лечения с использованием на первом этапе средств внеочаговой фиксации. Применение поэтапного метода лечения при нестабильных повреждениях таза находит все больше сторонников в Украине. Такая тактика присуща и российским коллегам, которые также сдержанно относятся к внутренней фиксации при нестабильных повреждениях таза [38].

Наибольшее признание среди специалистов получает концепция «контроля повреждений» (Damage Control), сутью которой является программированное этапное хирургическое лечение политравмы, с последующим окончательным лечением после полной стабилизации состояния пациентов (Damage Control Orthopedics) [39]. При нестабильных переломах таза концепция реализуется за счет ранней временной фиксации повреждений наименее травматичным способом с помощью щипцов Ganz. Второй этап включает коррекцию общего состояния пострадавшего. На третьем этапе производится окончательная ортопедическая коррекция перелома таза путем открытой репозиции и внутренней фиксации. Для уменьшения травматичности внутренней фиксации есть предложение В.М. Шаповалова с соавт. [40] об использовании принципа аппаратной фиксации с погружением конструкции в мягкие ткани. При тяжелом состоянии пациента в остром периоде травмы необходимо использовать аппараты внешней фиксации, а через две недели переходить на внутреннюю фиксацию [41].

При ротационно-нестабильных поврежде- ниях фиксацию лонного симфиза, переломов ветвей лонных костей выполняют реконструктивными и различными оригинальными пластинами [42, 43], в том числе малоинвазивным методом через минидоступ [44]. При вертикально-нестабильных повреждениях таза крестцовоподвздошное сочленение и переломы крестца фиксируют канюлированными винтами, реконструктивными мостовидными пластинами [45, 46], транспедикулярными системами [47]. Перспективным направлением в лечении нестабильных повреждений таза является сочетание методов внешней и внутренней фиксации в виде как одномоментного, так и последовательного их применения. Если переднее полукольцо таза можно надежно стабилизировать большинством аппаратов, то для фиксации заднего полукольца необходимо применение погружных конструкций. Комбинированный остеосинтез сочетает в себе преимущества объединяемых методов лечения и минимизирует недостатки каждого из них [48]. Стабильная фиксация как переднего, так и заднего полукольца таза позволяет проводить раннюю активизацию пациентов без риска потери репозиции, что наиболее актуально при политравме [49].

В связи с разносторонними взглядами на основные вопросы диагностики и лечения пациентов с повреждением таза, применяемые методы требуют стандартизации, четкого изложения показаний и противопоказаний к оперативному лечению, дополнительной информации о современной технике остеосинтеза таза.

\section{Заключение}

Догоспитальная помощь пострадавшим с переломами костей таза нуждается в серьезном пересмотре организационных мероприятий, в создании унифицированных средств иммобилизации пострадавших с политравмой, простых, но эффективных приемов обезболивания, введения противошоковых жидкостей на месте происшествия, способов транспортировки. Применение стержневых аппаратов внешней фиксации и шипцов Ганца при множественной и сочетанной травме в остром периоде обусловлено необходимостью сохранения витальных функций. Разработка новых, современных методов лечения данной категории пострадавших позволит получить лучшие функциональные результаты, сократить длительность пребывания в стационаре. Значительное количество различных методик и технологий лечения делают актуальным вопрос о степени эффективности каждой из них, сравнительном анализе показаний к каждому из методов лечения. 


\section{ЛИТЕРАТУРА}

1. Битчук ДД, Ковалев СИ, Истомин АГ, Чайенко ВП, Фадеев ОП. Внеочаговый остеосинтез таза при политравме. Ортопедия Травматология и Протезирование. 1996;(2):48-50.

2. Ушаков СА, Лукин СЮ, Истокский КН, Никольский АВ, Митрейкин ЮВ. Лечение травмы таза, осложненной повреждениями урогенитального тракта. Гений Ортопедии. 2011;(1):140-44.

3. Батпенов НД, Баймагамбетов ША, Махамбетчин ММ. Ранения кишки осколком кости при нестабильных переломах таза у больных с политравмой. Травматология и Ортопедия России. 2011;62(4):100-104.

4. Чемирис АИ, Нерянов ЮМ, Кудиевский АВ, и др. Ошибки и недостатки при оказании первой медицинской помощи пострадавшим с политравмой на догоспитальном этапе. Травма. 2003;4(5):587-90. 5. Гончаров СФ, Борисенко ЛВ. Задачи Всероссийской службы медицины катастроф по реализации целевой программы по безопасности дорожного движения. Медицина Катастроф. 2006;(3):5-7.

6. Шевченко ВС. Надання допомоги постраждалим 3 політравмою на етапі гострого періоду травматичної хвороби. Травма. 2003;4(4):454-56.

7. Бондаренко АВ, Пелеганчук ВА, Герасимова ОА. Госпитальная летальность при сочетанной травме и возможности ее снижения. Вестн. Травматологии и Ортопедии. 2004;(3):49-52.

8. Бичков ВВ. Основні напрямки оптимізації надання медичної допомоги постраждалим в дорожньо-транспортних пригодах. Травма. 2009;10(4):43033.

9. Wolinsky PR. Assessment and management of pelvic fracture in the hemodynamically unstable patient. Orthop Clin North Am. 1997 Jul;28(3):321-29.

10. Fitzgerald CA, Morse BC, Dente CJ. Pelvic ring fractures: has mortality improved following the implementation of damage control resuscitation? Am J Surg. 2014 Dec;208(6):1083-90; discussion 1089-90. doi: 10.1016/j.amjsurg.2014.09.002.

11. Abrassart S, Stern R, Peter R. Unstable pelvic ring injury with hemodynamic instability: What seems the best procedure choice and sequence in the initial management? Orthop Traumatol Surg Res. 2013;99(2):175-82 doi: 10.1016/j.otsr.2012.12.014.

12. Hou Z, Smith WR, Strohecker KA. Morgan Steven J. Hemodynamicallyunstable pelvic fracture management by advanced trauma life support guidelines results in high mortality. Orthopedics. 2012 Mar;35(3):e319-24. doi: 10.3928/01477447-20120222-29.

13. Müller ME, Schneider R, Willenegger H, Allgöwer M, ed. Manual of Internal fixation. SpringerVerlag Berlin Heidelberg; 1991. 410 p. doi

10.1007/978-3-662-02695-3.

14. Власов АП, Шевалаев ГА. Системный коагуляционно-литический дистресс-синдром при травматической болезни. Травматология и Ортопедия России. 2014;(1):80-85.

15. Бабоша ВА, Пастернак ВН, Лобанов ВН. Нестабильные повреждения таза - догоспитальный этап помощи. Ортопедия Травматология и Протезирование. 2002;(3):147-51.

16. Лобанов ГВ. Зовнішня фіксація пошкоджень таза (морфологічне та експериментально-механічне дослідження. Вісник Ортопедї Травматології та Протезування. 1999;25(1):141-42.

17. Лобанов ГВ, Оксимец ВМ, Островерхов ОА,
Боровой ИС. Выбор тактики лечения пострадавших с множественными повреждениями области тазобедренного сустава в остром периоде травмы. Літопис Травматології та Ортопедії. 2003;(1,2):4850 .

18. Колесников ВВ, Онищенко НС, Душкин ОФ. Использование противошокового костюма «Каштан» в лечении тяжелой сочетанной травмы. Вестн Травматологии Ортопедии им НН Приорова. 2002;(2):9-13.

19. Schildhauer TA, Wilber JH, Patterson BM. Posterior locked lateral compression injury of the pelvis: report of three cases. J Orthop Trauma. 2000 Feb;14(2):107-11.

20. Соколов ВА, Диденко АА, Макаров СА. Использование костюма "Каштан" для неинфузионной коррекции острой кровопотери и шока при травмах. Вестн Интенсив Терапии. 1993;(2-3):23-26. 21. Дятлов ММ. Повреждения кровеносных сосудов таза при его нестабильных переломах и вывихах у больных с сочетанной травмой. Вестн Травматологии Ортопедии им НН Приорова. 1999;(2): 27-33.

22. Failinger MS, McGanity PL. Unstable fractures of the pelvic ring. J Bone Joint Surg Am. 1992 Jun;74(5):781-91.

23. Shirley PJ. Transportation of the critically ill and injured patient. Hosp Med. 2000;61(6):406-10. doi: 10.12968/hosp.2000.61.6.1356.

24. Гуманенко ЕК, Шаповалов ВМ, Дулаев АК, Дыдыкин А В. Современные подходы к лечению пострадавших с нестабильными повреждениями тазового кольца. Воен-Мед Журн. 2003;(4):17-24.

25. Анкин ЛН Проблемы улучшения лечения повреждений таза. Ортопедия Травматология и Протезирование. 2009;(2):96-101.

26. Tile M, Helfet DL, Kellam JF, eds. Fractures of the Pelvis and Acetabulum. 3rd ed. Philadelphia, PA: Lippincott Williams \& Wilkins, 2003. 830 p.

27. Кукуруз ЯС, Бурлака ВВ, Бондаренко ВВ. Хiрургічне лікування при поднаній травмі таза і тазових органів. Вісник Ортопедії Травматологї ma Протезування. 2003;(2):39-44.

28. Rosseman R. A brief history of MAST. Pago: Wise Inc., 2001.

29. Пастернак ВН, Бабоша ВА, Лобанов ГВ. Нестабильные повреждения таза - помощь на этапе острого периода травмы с позиций медицины экстремальных состояний. $У_{\kappa р}$ Журн Екстремальноі Медицини ім ГО Можаєва. 2004;(4):59-63.

30. Mardanpour K1, Rahbar M. The outcome of surgically treated traumatic unstable pelvic fractures by open reduction and internal fixation. J Inj Violence Res. 2013 Jul;5(2):77-83. doi: 10.5249/jivr.v5i2.138.

31. Bassam D, Cephas GA, Ferguson KA, Beard LN, Young JS. A protocol for the initial management of unstable pelvic fractures. Am Surg. 1998 Sep;64(9):862-67.

32. Pape HC, Giannoudis P, Krettek C. The timing of fracture treatment in polytrauma patients: relevance of damage control orthopedic surgery. Am J Surg. 2002 Jun;183(6):622-29.

33. Бейдик ОВ, Левченко КК, Любицкий АП, Габаткин АИ, Афанасьев ДВ, Шевченко КВ, и др. Сравнительная оценка жесткости фиксации костных отломков спицевыми, стержневыми и спице-стержневыми способами наружного чрескостного остеосинтеза. Гений Ортопедии. 2003;(1):109-14. 34. Simonian PT, Routt ML Jr, Harrington RM, Tencer AF. Anterior versus posterior provisional fixa- 
tion in the unstable pelvis. A biomechanical comparison. Clin Orthop Relat Res. 1995 Jan;(310):245-51.

35. Черкес-Заде ДИ, Лапшин ВБ, Ножин НП, Каменев АФ. Лечение повреждений таза с использованием аппаратов наружной фиксации. Oртопедия Травматология и Протезирование. 1993;(3):44-47.

36. Анкин ЛН, Анкин НЛ. Повреждения таза и переломы вертлужной впадины. Киев, Украина: Книга плюс; 2007. 216 с.

37. Клімовицький ВГ, Пастернак ВП, Поляченко ЮВ. Політравма - патогенетичне обгрунтування лікувального комплексу гострого періоду травматичної хвороби. Украӥнський Журнал Екстремальноі Медииини ім ГО Можаєва. 2002;3(1):11-16.

38. Peitzman AB, Rhodes M, Schwab CW, Yealy DM, Fabian TC. The Trauma manual. 2nd ed. Lippincott: Williams and Wilkins; 2003. 310 p.

39. Džupa V, Pavelka T, Taller S. Pelvic ring injury as part of multiple trauma. Rozhl Chir. 2014;93(5):292-96. 40. Шаповалов ВМ, Дулаев АК, Дыдыкин А.В. Эксперементальная разработка и клиническое приминение минимально инвазивной внутренней стержневой фиксации тазового кольца. $B e$ стн Травматологии и Ортопедии им НН Приорова. $2001 ;(4): 33-37$.

41. Pohlemann T. Prymary treatment of politrauma patients with pelvis trauma as leading injury. Eur $J$ Trauma. 2002;(1):41-42.

42. Balbachevsky D, Belloti JC, Doca DG, Jannarelli B, Junior JA, Fernandes HJ, et al. Treatment of pelvic fractures - a national survey. Injury. 2014 Nov;45(Suppl 5):S46-51. doi: 10.1016/S0020-1383(14)70021-X.

43. Бялик ЕИ, Файн АМ. Этапное лечение повреждений в области лонного сочленения с применением оригинального фиксатора у пострадавших с сочетанной травмой таза. Политравма. 2013;(4):30-34.

44. Hiesterman TG, Hill BW, Cole PA. Surgical technique: a percutaneous method of subcutaneous fixation for the anterior pelvic ring: the pelvic bridge. Clin Orthop Relat Res. 2012 Aug;470(8):2116-23. doi: 10.1007/s11999-012-2341-4.

45. Chen HW, Liu GD, Ou S, Zhao GS, Pan J. Treatment of unstable sacral fractures with percutaneous reconstruction plate internal fixation. Acta Cir Bras. 2012 May;27(5):338-42. doi: 10.1590/S010286502012000500010 .

46. Li C. L. Clinical comparative analysis on unstable pelvic fractures in the treatment with percutaneous sacroiliac screws and sacroiliac joint anterior plate fixation. Eur Rev Med Pharmacol Sci. 2014;18(18):2704-8. 47. Ханин МЮ, Минасов БШ, Минасов ТБ, Якупов РР, Загитов БГ. Ортопедический damagecontrol при повреждениях таза у пациентов с политравмой. Практ Медицина. 2011;(6):122-25.

48. Смирнов АА. Оперативное лечение вертикально-нестабильных повреждений таза (тип С по классификации АО). Травматология и Ортопедия России. 2012;(1):73-76.

49. Донченко СВ, Дубров ВЭ, Слиняков ЛЮ, Черняев АВ, Лебедев АФ, и др. Алгоритм хирургического лечения нестабильных повреждений тазового кольца. Вестн Травматологии и Ортопедии им НН Приорова. 2013;(4):9-16.

\section{REFERENCES}

1. Bitchuk DD, Kovalev SI, Istomin AG, Chaienko VP, Fadeev OP. Vneochagovyi osteosintez taza pri politravme [Extrafocal pelvis osteosynthesis in pol- ytrauma]. Ortopediia Travmatologiia i Protezirovanie. 1996;(2):48-50.

2. Ushakov SA, Lukin SIu, Istokskii KN, Nikol'skii $\mathrm{AV}$, Mitreikin IuV. Lechenie travmy taza, oslozhnennoi povrezhdeniiami urogenital'nogo trakta [Treatment of pelvic trauma complicated by lesions of the urogenital tract]. Genii Ortopedii. 2011;(1):140-44.

3. Batpenov ND? Baimagambetov ShA, Makhambetchin MM. Raneniia kishki oskolkom kosti pri nestabil'nykh perelomakh taza $\mathrm{u}$ bol'nykh $\mathrm{s}$ politravmoi [Wound gut bone splinter when the unstable pelvic fractures in patients with multiple injuries]. Travmatologiia i Ortopediia Rossii. 2011;62(4):100-104.

4. Chemiris AI, Nerianov IuM, Kudievskii AV, i dr. Oshibki i nedostatki pri okazanii pervoi meditsinskoi pomoshchi postradavshim s politravmoi na dogospital'nom etape [Mistakes and shortcomings in the provision of first aid to victims with polytrauma at the prehospital stage]. Travma. 2003;4(5):587-90.

5. Goncharov SF, Borisenko LV. Zadachi Vserosiiskoi sluzhby meditsiny katastrof po realizatsii tselevoi programmy po bezopasnosti dorozhnogo dvizheniia [Objectives of All-Russian disaster medicine service for the implementation of targeted road safety programs]. Meditsina Katastrof. 2006;(3):5-7.

6. Shevchenko VS. Nadannia dopomogi postrazhdalim $\mathrm{Z}$ poltravmoiu na etap gostrogo perodu travmatichno khvorobi [Assistance to the victims of polytrauma during the acute period of traumatic disease]. Travma. 2003;4(4):454-56.

7. Bondarenko AV, Peleganchuk VA, Gerasimova OA. Gospital'naia letal'nost' pri sochetannoi travme i vozmozhnosti ee snizheniia [Hospital mortality in combined injury and the possibility of its reduction]. Vestn. Travmatologii i Ortopedii. 2004;(3):49-52.

8. Bichkov VV. Osnovn napriamki optimzats nadannia medichno dopomogi postrazhdalim v dorozhn'otransportnikh prigodakh [The main directions of optimization of medical care to victims of road accidents].

Travma. 2009;10(4):430-33.

9.Wolinsky PR. Assessment and management of pelvic fracture in the hemodynamically unstable patient. Orthop Clin North Am. 1997 Jul;28(3):321-29.

10.Fitzgerald CA, Morse BC, Dente CJ. Pelvic ring fractures: has mortality improved following the implementation of damage control resuscitation? Am J Surg. 2014 Dec;208(6):1083-90; discussion 1089-90. doi: 10.1016/j.amjsurg.2014.09.002.

11.Abrassart S, Stern R, Peter R. Unstable pelvic ring injury with hemodynamic instability: What seems the best procedure choice and sequence in the initial management? Orthop Traumatol Surg Res. 2013;99(2):175-82 doi: 10.1016/j.otsr.2012.12.014.

12.Hou Z, Smith WR, Strohecker KA. Morgan Steven J. Hemodynamicallyunstable pelvic fracture management by advanced trauma life support guidelines results in high mortality. Orthopedics. 2012 Mar;35(3):e319-24. doi: 10.3928/01477447-20120222-29.

13. Müller ME, Schneider R, Willenegger H, Allgöwer M, ed. Manual of Internal fixation. Springer-Verlag Berlin Heidelberg; 1991. 410 p. doi: 10.1007/978-3662-02695-3.

14. Vlasov AP, Shevalaev GA. Sistemnyi koaguliatsionno-liticheskii distress-sindrom pri travmaticheskoi bolezni [System coagulation-lytic distress syndrome in traumatic disease]. Travmatologiia i Ortopediia Rossii. 2014;(1):80-85.

15. Babosha VA, Pasternak VN, Lobanov VN. 
Nestabil'nye povrezhdeniia taza-dogospital'nyi etap pomoshchi [Unstable pelvic damage, prehospital assistance]. Ortopediia Travmatologiia i Protezirovanie. 2002;(3):147-51.

16. Lobanov GV. Zovnshnia fksatsia poshkodzhen' taza (morfologchne ta eksperimental'no-mekhanchne dosldzhennia [External fixation of pelvic injuries (morphological and experimental mechanical study]. Vsnik Ortoped Travmatolog ta Protezuvannia. 1999;25(1):141-42.

17. Lobanov GV, Oksimets VM, Ostroverkhov OA, Borovoi IS. Vybor taktiki lecheniia postradavshikh $s$ mnozhestvennymi povrezhdeniiami oblasti tazobedrennogo sustava $\mathrm{V}$ ostrom periode travmy [The choice of tactics of treatment of patients with multiple injuries of the hip region during the acute phase of injury]. Ltopis Travmatolog ta Ortoped. 2003;(1,2):48-50.

18. Kolesnikov VV, Onishchenko NS, Dushkin OF. Ispol'zovanie protivoshokovogo kostiuma «Kashtan» v lechenii tiazheloi sochetannoi travmy [Using antishock suit "chestnut" in the treatment of severe combined trauma]. Vestn Travmatologii Ortopedii im NN Priorova. $2002 ;(2): 9-13$.

19. Schildhauer TA, Wilber JH, Patterson BM. Posterior locked lateral compression injury of the pelvis: report of three cases. J Orthop Trauma. 2000 Feb;14(2):107-11.

20. Sokolov VA, Didenko AA, Makarov SA. Ispol'zovanie kostiuma "Kashtan" dlia neinfuzionnoi korrektsii ostroi krovopoteri i shoka pri travmakh [Using Costume "Chestnut" for a correction fluid of acute blood loss and shockwith injuries]. Vestn Intensiv Terapii. 1993;(2-3):23-26.

21. Diatlov MM. Povrezhdeniia krovenosnykh sosudov taza pri ego nestabil'nykh perelomakh i vyvikhakh u bol'nykh s sochetannoi travmoi [Damage to the blood vessels of the pelvis in its unstable fractures and dislocations in patients with combined trauma]. Vestn Travmatologii Ortopedii im NN Priorova. 1999;(2): 27-33.

22. Failinger MS, McGanity PL. Unstable fractures of the pelvic ring. J Bone Joint Surg Am. 1992 Jun;74(5):781-91.

23. Shirley PJ. Transportation of the critically ill and injured patient. Hosp Med. 2000;61(6):406-10. doi: 10.12968/hosp.2000.61.6.1356.

24. Gumanenko EK, Shapovalov VM, Dulaev AK, Dydykin AV. Sovremennye podkhody k lecheniiu postradavshikh s nestabil'nymi povrezhdeniiami tazovogo kol'tsa [Current approaches to the treatment of patients with unstable pelvic ring injuries]. Voen-Med Zhurn. 2003;(4):17-24.

25. Ankin LN. Problemy uluchsheniia lecheniia povrezhdenii taza [Problems of improving the treatment of injuries of the pelvis]. Ortopediia Travmatologiia i Protezirovanie. 2009;(2):96-101.

26. Tile M, Helfet DL, Kellam JF, eds. Fractures of the Pelvis and Acetabulum. 3rd ed. Philadelphia, PA: Lippincott Williams \& Wilkins, 2003. 830 p.

27. Kukuruz IS, Burlaka VV, Bondarenko VV. Khrurgchne lkuvannia pri poednani travm taza tazovikh organv [Surgical treatment of concomitant injury of the pelvis and pelvic organs]. Vsnik Ortoped Travmatolog ta Protezuvannia. 2003;(2):39-44.

28. Rosseman R. A brief history of MAST. Pago: Wise Inc., 2001.

29. Pasternak VN, Babosha VA, Lobanov GV. Nestabil'nye povrezhdeniia taza - pomoshch' na etape ostrogo perioda travmy $\mathrm{s}$ pozitsii meditsiny ekstremal'nykh sostoianii [Unstable pelvic injuries - assistance at the stage of the acute period of injury from the standpoint of medicine of extreme conditions]. Ukr zhurn ekstremal'no meditsini m GO Mozhaєva. 2004;(4):59-63

30. Mardanpour K1, Rahbar M. The outcome of surgically treated traumatic unstable pelvic fractures by open reduction and internal fixation. J Inj Violence Res. 2013 Jul;5(2):77-83. doi: 10.5249/jivr.v5i2.138.

31. Bassam D, Cephas GA, Ferguson KA, Beard LN, Young JS. A protocol for the initial management of unstable pelvic fractures. Am Surg. 1998 Sep;64(9):862-67. 32. Pape HC, Giannoudis P, Krettek C. The timing of fracture treatment in polytrauma patients: relevance of damage control orthopedic surgery. Am J Surg. 2002 Jun;183(6):622-29.

33. BeidikOV, Levchenko KK, Liubitskii AP, Gabatkin AI, Afanas'ev DV, Shevchenko KV, i dr. Sravnitel'naia otsenka zhestkosti fiksatsii kostnykh otlomkov spitsevymi, sterzhnevymi i spitse-sterzhnevymi sposobami naruzhnogo chreskostnogo osteosinteza [Comparative evaluation of stiffness fixation of bone fragments spoke, and spoke rod-rod outer ways chreskostnogo osteosynthesis]. Genii Ortopedii. 2003;(1):109-14.

34. Simonian PT, Routt ML Jr, Harrington RM, Tencer AF. Anterior versus posterior provisional fixation in the unstable pelvis. A biomechanical comparison. Clin Orthop Relat Res. 1995 Jan;(310):245-51.

35. Cherkes-Zade DI, Lapshin VB, Nozhin NP, Kamenev AF. Lechenie povrezhdenii taza $\mathrm{s}$ ispol'zovaniem apparatov naruzhnoi fiksatsii [Treatment of injuries of the pelvis using an external fixator]. Ortopediia Travmatologiia i Protezirovanie. 1993;(3):44-47.

36. Ankin LN, Ankin NL. Povrezhdeniia taza i perelomy vertluzhnoi vpadiny [Damage to the pelvic and acetabular fractures]. Kiev, Ukraina: Kniga plius; 2007. $216 \mathrm{p}$.

37. Klmovits'kii VG, Pasternak VP, Poliachenko IuV. Poltravma - patogenetichne obgruntuvannia lkuval'nogo kompleksu gostrogo perodu travmatichno khvorobi [Polytrauma - pathogenetic substantiation of a medical complex of the acute period of traumatic disease]. Ukrans'kii Zhurnal Ekstremal'no Meditsini $m$ GO Mozhacva. 2002;3(1):11-16.

38. Peitzman AB, Rhodes M, Schwab CW, Yealy DM, Fabian TC. The trauma manual. 2nd ed. Lippincott: Williams and Wilkins; 2003. 310 p.

39. Džupa V, Pavelka T, Taller S. Pelvic ring injury as part of multiple trauma. Rozhl Chir. 2014;93(5):292-96.

40. Shapovalov VM, Dulaev AK, Dydykin A.V. Eksperemental'naia razrabotka i klinicheskoe priminenie minimal'no invazivnoi vnutrennei sterzhnevoi fiksatsii tazovogo kol'tsa [Experimental and clinical development of application of minimally invasive internal fixation of pelvic ring core]. Vestn Travmatologii i Ortopedii im NN Priorova. 2001;(4):33-37.

41. Pohlemann T. Prymary treatment of politrauma patients with pelvis trauma as leading injury. Eur $J$ Trauma. 2002;(1):41-42.

42. Balbachevsky D, Belloti JC, Doca DG, Jannarelli B, Junior JA, Fernandes HJ, et al. Treatment of pelvic fractures - a national survey. Injury. 2014 Nov;45(Suppl 5):S46-51. doi: 10.1016/S0020-1383(14)70021-X.

43. Bialik EI, Fain AM. Etapnoe lechenie povrezhdenii $\mathrm{v}$ oblasti lonnogo sochleneniia $\mathrm{s}$ primeneniem original'nogo fiksatora $\mathrm{u}$ postradavshikh s sochetannoi 
travmoi taza [Staged treatment of lesions in the symphysis pubis with the original lockin victims with concomitant injury of the pelvis]. Politravma. 2013;(4):30-34. 44. Hiesterman TG, Hill BW, Cole PA. Surgical technique: a percutaneous method of subcutaneous fixation for the anterior pelvic ring: the pelvic bridge. Clin Orthop Relat Res. 2012 Aug;470(8):2116-23. doi: 10.1007/ s11999-012-2341-4.

45. Chen HW, Liu GD, Ou S, Zhao GS, Pan J. Treatment of unstable sacral fractures with percutaneous reconstruction plate internal fixation. Acta Cir Bras. 2012 May;27(5):338-42. doi: 10.1590/S010286502012000500010.

46. Li C. L. Clinical comparative analysis on unstable pelvic fractures in the treatment with percutaneous sacroiliac screws and sacroiliac joint anterior plate fixation. Eur Rev Med Pharmacol Sci. 2014;18(18):2704-8.

\section{Адрес для корреспонденции}

79010, Украина, г. Львов, ул. Пекарская, д. 69,

Львовский национальный медицинский университет им. Данила Галицкого, кафедра медицины катастроф и военной медицины, тел. раб.: +38 (032) 260-08-28, e-mail: kozopas@ukr.net,

Козопас Виктор Степанович

\section{Сведения об авторах}

Козопас В.С., к.м.н., ассистент кафедры медицины катастроф и военной медицины Львовского национального медицинского университета им. Данила Галицкого.
47. Khanin MIu, Minasov BSh, Minasov TB, Iakupov PP, Zagitov BG. Ortopedicheskii damagecontrol pri povrezhdeniiakh taza u patsientov s politravmoi [Orthopedic damage-control with pelvic lesions in patients with multiple injuries]. Prakt Meditsina. 2011;(6):122-25.

48. Smirnov AA. Operativnoe lechenie vertikal'nonestabil'nykh povrezhdenii taza (tip $\mathrm{S}$ po klassifikatsii AO) [Surgical treatment of vertically unstable pelvic injuries (type $\mathrm{C}$ by AO classification)]. Travmatologiia i Ortopediia Rossii. 2012;(1):73-76.

49. Donchenko SV, Dubrov VE, Sliniakov LIu, Cherniaev AV, Lebedev AF, i dr. Algoritm khirurgicheskogo lecheniia nestabil'nykh povrezhdenii tazovogo kol'tsa [The algorithm of surgical treatment of unstable pelvic ring injuries]. Vestn Travmatologii i Ortopedii im NN Priorova. 2013;(4):9-16.

\section{Address for correspondence}

79010, Ukraine,

Lviv. Pekarskaya st., 69 ,

Lviv National Medical University

named after Danila Galitsky,

Department of disaster medicine

and Military Medicine.

Tel.: 38 (032) 260-08-28

E-mail: kozopas@ukr.net

Kozopas Viktor Stepanovich

\section{Information about the authors}

Kozopas V.S. PhD, Assistant of department of disaster medicine and military medicine of Danylo Halytsky Lviv National Medical University.

Received 19.07.2016 